\title{
MODELOS DE CHECKLIST COMO FERRAMENTA NO PROCESSO DE INSPEÇÃO PREDIAL
}

\author{
BÖES, JEFERSON SPIERING \\ Professor \\ Faculdade Ari de Sá (FAS) \\ Ceará; Brasil \\ boes.jeferson@gmail.com
}

\section{RESUMO}

A inspeção predial tem como papel principal a identificação das manifestações patológicas e falhas presentes nas edificações e sua correta classificação quanto ao grau de risco para posterior correção. Esta identificação deve envolver todos os sistemas, subsistemas, elementos e componentes constituintes de uma edificação, gerando um grande volume de informações a serem coletadas, processadas e analisadas. As listas de verificações são ferramentas que auxiliam o processo de inspeção predial, fornecendo um conjunto de tópicos a serem vistoriados para cada sistema construtivo, permitindo aos inspetores registrar in loco as manifestações patológicas e falhas, como também, as características técnicas, de uso e de manutenção da edificação, objetivando um maior controle de qualidade no desenvolvimento do laudo de inspeção predial, como também, a organização os dados coletados de forma clara e objetiva. O presente artigo tem por objetivo apresentar modelos de listas de verificações para os principais sistemas construtivos, de modo que sirvam como ferramenta na identificação e classificação do grau de risco no processo de inspeção predial. Os modelos foram desenvolvidos a partir de uma revisão sistemática da literatura em conjunto com a análise de diversos laudos de inspeção predial e validados através de 20 aplicações em edificações diferentes. Como contribuição, os modelos desenvolvidos apresentam as manifestações patológicas e falhas mais recorrentes nos sistemas construtivos e podem ser aplicados em todos os níveis de inspeções prediais, servindo como subsídio aos inspetores no atendimento das leis municipais, que obrigam as inspeções periódicas nas edificações..

Palavras-chave: checklist, inspeção predial, manifestação patológica, Falhas.

\section{ABSTRACT}

Building inspection has as its main role the identification of pathological manifestations and faults present in buildings and their correct classification as to the degree of risk for later correction. This identification should involve all systems, subsystems, elements and components of a building, generating a large amount of information to be collected, processed and analyzed. Since checklists are tools that aid the building inspection process, they provide a set of items to use for each building system, allowing inspectors to record on the spot as pathological manifestations and failures, as well as technical techniques, use and maintenance of the edition, aiming at a better quality control in the development of the building inspection, as well as a clear and objective organization of the collected data. The purpose of this paper is to present checklist models for the main building systems, so that they serve as a risk identification and classification tool in the building inspection process. The models were subjected to a systematic literature review together with an analysis of several building inspection reports and validated through 20 applications in different buildings. As a contribution, the models presented as pathological manifestations and most recurrent failures in building systems and can be detected at all levels of building inspections, serving as an aid to inspectors in compliance with municipal laws, which are mandatory as periodic inspections in editions.

Keywords: checklists, buiding inspection, pathological manifestation, failures.

\section{INTRODUÇÃO}

A inspeção predial insere-se no rol de ferramentas da Engenharia Diagnóstica em edificações, que é a disciplina de ações proativas no sentido da qualidade, por meio de diagnósticos, prognósticos e prescrições técnicas que favorecem a boa gestão predial no decorrer da vida útil (GOMIDE; NETO; GULLO, 2014). Ela se destaca como uma excelente ferramenta de identificação de anomalias, manifestações patológicas e falhas nas edificações, oportunizando um diagnóstico, definindo as prioridades e as recomendações técnicas acerca dos sistemas construtivos (BÖES, 2017). 
É de conhecimento técnico que os sistemas construtivos e seus elementos, necessitam de atividades de manutenção ao longo de toda sua vida útil, para garantir níveis aceitáveis de desempenho e segurança, previstos em projeto. Apesar de normas (ABNT, 2012; ABNT 2015), preconizarem o planejamento das manutenções, as inspeções demandam uma significativa quantidade de itens a serem inspecionados, gerando grandes volumes de informações. Neste sentido, o uso de checklists desenvolvidos previamente às inspeções podem contribuir para mitigar falhas na etapa de identificação das anomalias e gerenciar as informações geradas.

\section{REVISÃO DA LITERATURA}

\subsection{Inspeção Predial}

A inspeção predial é uma análise isolada ou combinada das condições técnicas, de uso e de manutenção da edificação (IBAPE, 2012), resultantes em um laudo (IBRAENG, 2015). O objetivo das inspeções é determinar as irregularidades prediais que possam prejudicar a qualidade da edificação (GOMIDE; NETO; GULLO, 2014).

As inspeções podem ser consideradas um instrumento, baseado na análise visual da construção, que mostram eventuais danos no todo ou em partes, registrando tais resultados em laudos (PACHECO; OLIVEIRA; SILVA FILHO, 2013), envolvendo etapas de criação de instrumentos, coletas de dados de campo, análise de informações e documentação dos resultados, os quais são posteriormente interpretados (BALLADO; TRUPP; LIU, 2003).

\subsection{Checklists}

Os checklists são formulários elaborados pelos inspetores para verificação e anotação in loco das características técnicas, de uso e de manutenção de uma edificação. Os objetivos dos checklists é registrar durante as vistorias, as características gerais da edificação e as características dos diversos sistemas construtivos, as práticas de uso e manutenção adotadas pelos usuários e administradores, e as anomalias e falhas porventura constatadas (BÖES, 2017).

Elas têm por objetivo proporcionar um maior controle de qualidade sobre a produção dos laudos de inspeção predial, como também, organizar os dados analisados de forma objetiva (BÖES, 2017), garantindo assim, que todos os sistemas e elementos importantes que compõe uma edificação tenham sido analisados e seus graus de segurança identificados. (VERZOLA; MARCHIORI; ARAGON, 2014).

Estudos desenvolvidos (VERZOLA; MARCHIORI; ARAGON, 2014; BALLADO; TRUPP; LIU, 2003; SUNKPHO; GARRETT JR; McNeil, 2005; STEINBERG, 2009) apresentam ferramentas desenvolvidas com foco na inspeção com o uso de tecnologias em sistemas voltados para infraestrutura. Para cada inspeção predial deverá ser elaborada um adaptada os checklist de acordo com a tipologia e peculiaridade do empreendimento à ser inspecionado. Deve-se levar em consideração a idade, a complexidade, seus sistemas construtivos e equipamentos, o grau de conservação e a estratégia de inspeção (BÖES, 2017).

Apesar de tal importância, as listas de verificação por si só, não são suficientes para resolver os problemas de manutenção predial, sugerindo que ela possa integrar um conjunto de ações acerca da avaliação (VERZOLA; MARCHIORI; ARAGON, 2014).

\subsection{Método GUT (Gravidade, Urgência e Tendência)}

As anomalias e falhas devem ser priorizadas conforme o seu grau de risco, orientando assim, os usuários acerca das medidas à serem tomadas. Existem diversos métodos para avaliação destes riscos, com destaque para o Método GUT aplicado à inspeção Predial (VERZOLA; MARCHIORI; ARAGON, 2014), em que adapta o Método GUT (Gravidade, Urgência e Tendência) (KEPNER; TREGOE, 1991), para a inspeção predial.

Todas as anomalias e falhas ao avaliadas em relação à sua criticidade e gravidade, em que são atribuídas notas de 1 a 5 , em uma ordem crescente, em que o 1 é o menos grave e o 5 o mais grave. Ao final, as notas são multiplicadas, conforme a figura 1 (KEPNER; TREGOE, 1991), que indicará a prioridade do problema, como ilustra o quadro 1 (VERZOLA; MARCHIORI; ARAGON, 2014). 
Equação 1 - Cálculo método GUT

$$
P=G \times U x T
$$

Quadro 1 - Método GUT aplicado a Inspeção Predial

\begin{tabular}{|c|c|c|c|c|}
\hline Valor & Gravidade (G) & Urgência (U) & Tendência (T) & GxU $\times T$ \\
\hline 1 & $\begin{array}{l}\text { Nenhum risco à saúde, à integridade física dos } \\
\text { usuários, ao meio ambiente ou ao edifício. } \\
\text { Mínima depreciação do patrimônio. Eventuais } \\
\text { trocas de componentes, nenhum } \\
\text { comprometimento do valor imobiliário. }\end{array}$ & Não tem pressa & Não vai piorar & \\
\hline 2 & $\begin{array}{l}\text { Sem risco à integridade física dos usuários, } \\
\text { sem risco ao meio ambiente, pequenos } \\
\text { incômodos estéticos ou de utilização, } \\
\text { pequenas substituições de componentes ou } \\
\text { sistemas, reparos de manutenção planejada } \\
\text { para recuperação ou prolongamento de vida } \\
\text { útil. Prejuízo financeiro pequeno. }\end{array}$ & $\begin{array}{l}\text { Pode esperar um } \\
\text { pouco }\end{array}$ & $\begin{array}{c}\text { Vai piorar a longo } \\
\text { prazo }\end{array}$ & \\
\hline 3 & $\begin{array}{l}\text { Risco à saúde dos usuários, desconfortos na } \\
\text { utilização dos sistemas, deterioração passível } \\
\text { de restauração/reparo, podendo provocar } \\
\text { perda de funcionalidade com prejuízo à } \\
\text { operação direta de sistemas ou componentes. } \\
\text { Danos ao meio ambiente passíveis de reparo. } \\
\text { Prejuízo financeiro médio. }\end{array}$ & $\begin{array}{l}\text { O mais cedo } \\
\text { possível }\end{array}$ & $\begin{array}{l}\text { Vai piorar em } \\
\text { médio prazo }\end{array}$ & \\
\hline 4 & $\begin{array}{l}\text { Risco de ferimentos aos usuários, danos } \\
\text { reversíveis ao meio ambiente ou ao edifício. } \\
\text { Impacto recuperável com o comprometimento } \\
\text { parcial do desempenho e funcionalidade (vida } \\
\text { útil) do sistema que afeta parcialmente a saúde } \\
\text { dos usuários ou o meio ambiente. Prejuízo } \\
\text { financeiro alto. }\end{array}$ & Urgente & $\begin{array}{l}\text { Vai piorar em } \\
\text { pouco tempo }\end{array}$ & \\
\hline 5 & $\begin{array}{l}\text { Risco de morte, risco de desabamento/colapso } \\
\text { pontual ou generalizado, iminência de } \\
\text { Incêndio, impacto irrecuperável com perda } \\
\text { excessiva do desempenho e funcionalidade, } \\
\text { comprometimento irrecuperável da vida útil } \\
\text { do sistema causando dano grave à saúde dos } \\
\text { usuários ou ao meio ambiente. Prejuízo } \\
\text { financeiro muito algo. }\end{array}$ & Ação imediata & $\begin{array}{l}\text { Vai piorar } \\
\text { rapidamente }\end{array}$ & \\
\hline
\end{tabular}

Fonte: VERZOLA; MARCHIORI; ARAGON (2014)

\section{METODOLOGIA}

O desenvolvimento da pesquisa ocorreu em cinco etapas, conforme ilustra a figura 1. A primeira etapa consistiu em uma revisão bibliográfica acerca das principais manifestações patológicas nas edificações e de checklists voltados para inspeções, como também analisar laudos de inspeções prediais, com objetivo de obter melhor entendimento dos principais problemas identificados. De posse da revisão bibliográfica realizou-se o desenvolvimento da primeira versão dos checklists.

Os checklists podem ser desenvolvidos de duas formas: (i) Sistemas Construtivas; ou (ii) Pavimentos. Por sistemas construtivos, os checklists são divididos por sistema construtivos, com os elementos que o compõe a serem inspecionados. Neste caso, um checklist irá contemplar mais de um pavimento. No caso de checklist divididos por pavimentos, todos sistemas construtivos estão inseridos em um único checklist. O quadro 2 apresenta uma comparação. 
Figura 1 - Delineamento da pesquisa

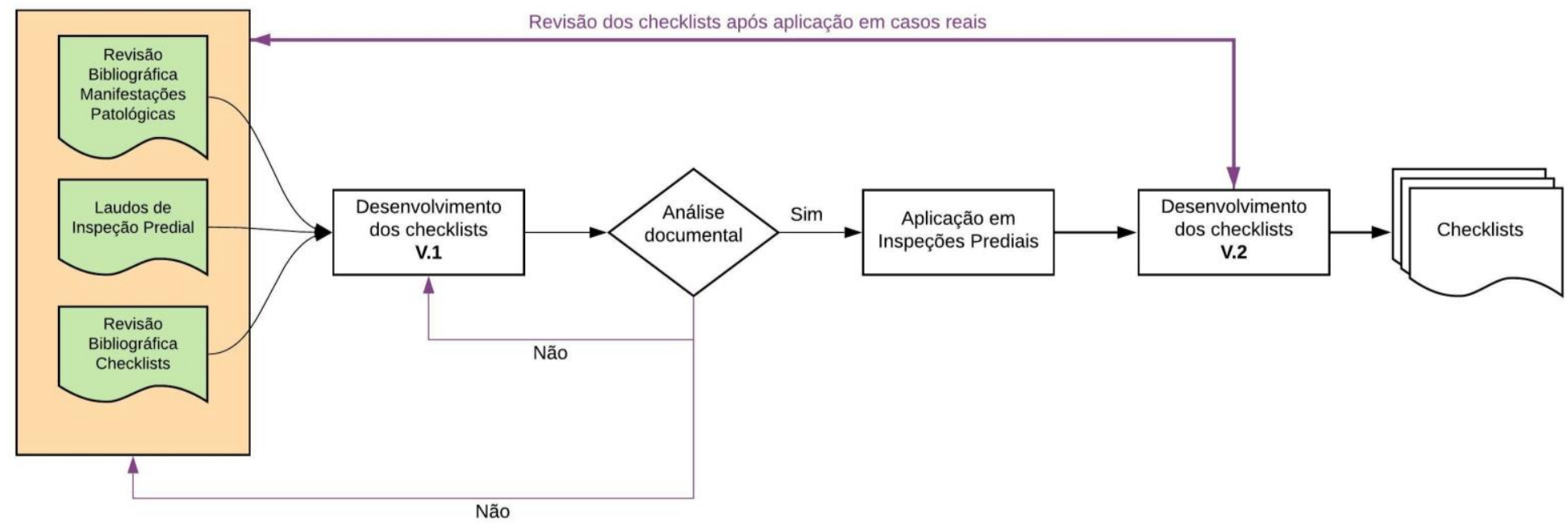

Quadro 2 - Vantagem e desvantagens dos modelos de checklist

\begin{tabular}{|c|c|c|}
\hline Modelo Checklist & Vantagem & Desvantagem \\
\hline \multirow[t]{2}{*}{ Sistema Construtivo } & $\begin{array}{c}\text { Facilita a identificação/registro dos } \\
\text { sistemas e de seus componentes } \\
\text { principais. }\end{array}$ & \multirow{2}{*}{$\begin{array}{l}\text { Requer maior tempo de inspeção, } \\
\text { pois a equipe irá retornar várias vezes } \\
\text { ao mesmo pavimento. }\end{array}$} \\
\hline & $\begin{array}{l}\text { Há um maior foco sobre o sistema } \\
\text { construtivo. }\end{array}$ & \\
\hline \multirow[t]{2}{*}{ Pavimento } & $\begin{array}{c}\text { Há uma redução do tempo } \\
\text { desprendido na inspeção, onde os } \\
\text { inspetores passam apenas uma vez } \\
\text { em cada pavimento. }\end{array}$ & $\begin{array}{l}\text { Os checklists podem se tornar } \\
\text { maiores. }\end{array}$ \\
\hline & $\begin{array}{l}\text { Facilita a identificação/registro dos } \\
\text { sistemas dos equipamentos e de suas } \\
\text { partes, elementos e componentes. }\end{array}$ & $\begin{array}{c}\text { Não há um foco específico sobre } \\
\text { cada sistema construtivo. }\end{array}$ \\
\hline
\end{tabular}

Para a presente pesquisa, definiu-se o modelo de checklist por sistema construtivo, em virtude de proporcionar uma ferramenta mais ampla aos inspetores. Após desenvolvida a primeira versão, analisou-se os modelos e confrontou-se através de um grupo focal, sobre a aderência deles frente a literatura.

Os modelos então, foram aplicados em 20 inspeções prediais realizadas na cidade de Fortaleza/CE, com o objetivo de validar sua aplicabilidade. Após as inspeções, os modelos foram novamente confrontados em um grupo focal, onde os inspetores apontavam as dificuldades, falhas e sugestões através de sua experiência prática na utilização dos modelos. Neste sentido, os modelos foram aperfeiçoados e gerados a versão V.2..

\section{RESULTADOS}

Ao todo, foram desenvolvidos 11 checklists, apresentados nos quadros 3 a 14, separados nos principais sistemas construtivos, totalizando 137 itens à serem inspecionados. Os modelos têm como função: (i) orientar os itens à serem inspecionados por sistemas construtivos; (ii) servir como ferramenta de coleta e gestão das informações em campo.

Em cada checklist, o inspetor poderá apontar se há ou não a presenta de tal anomalia ou falha, registrar o número da fotografia, indicar o local em que foi identificada e preencher o método GUT, gerando o Grau de Risco. 
Quadro 3 - Checklist Vedações (externas e internas) e Revestimentos

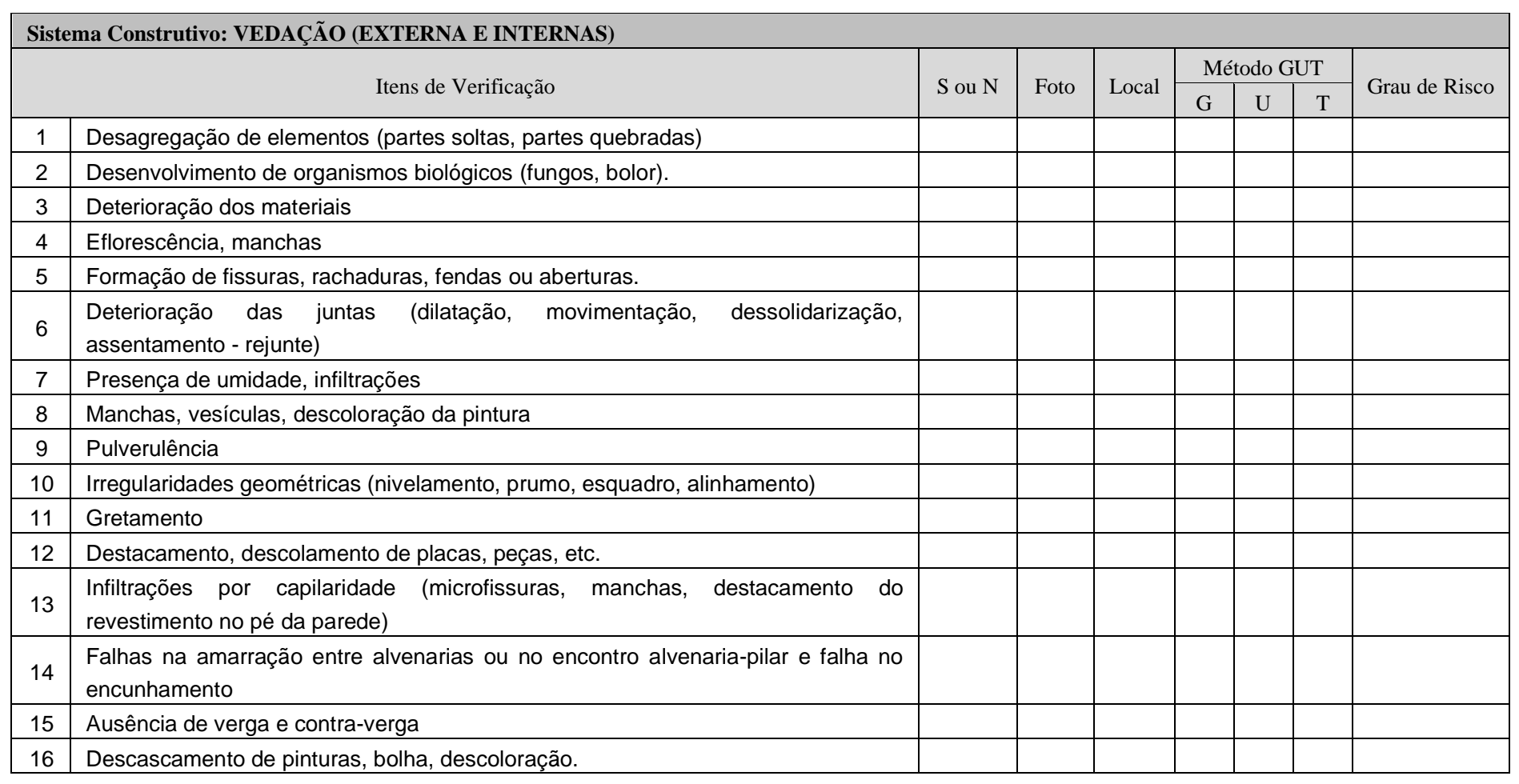

Quadro 4-Checklist Cobertura

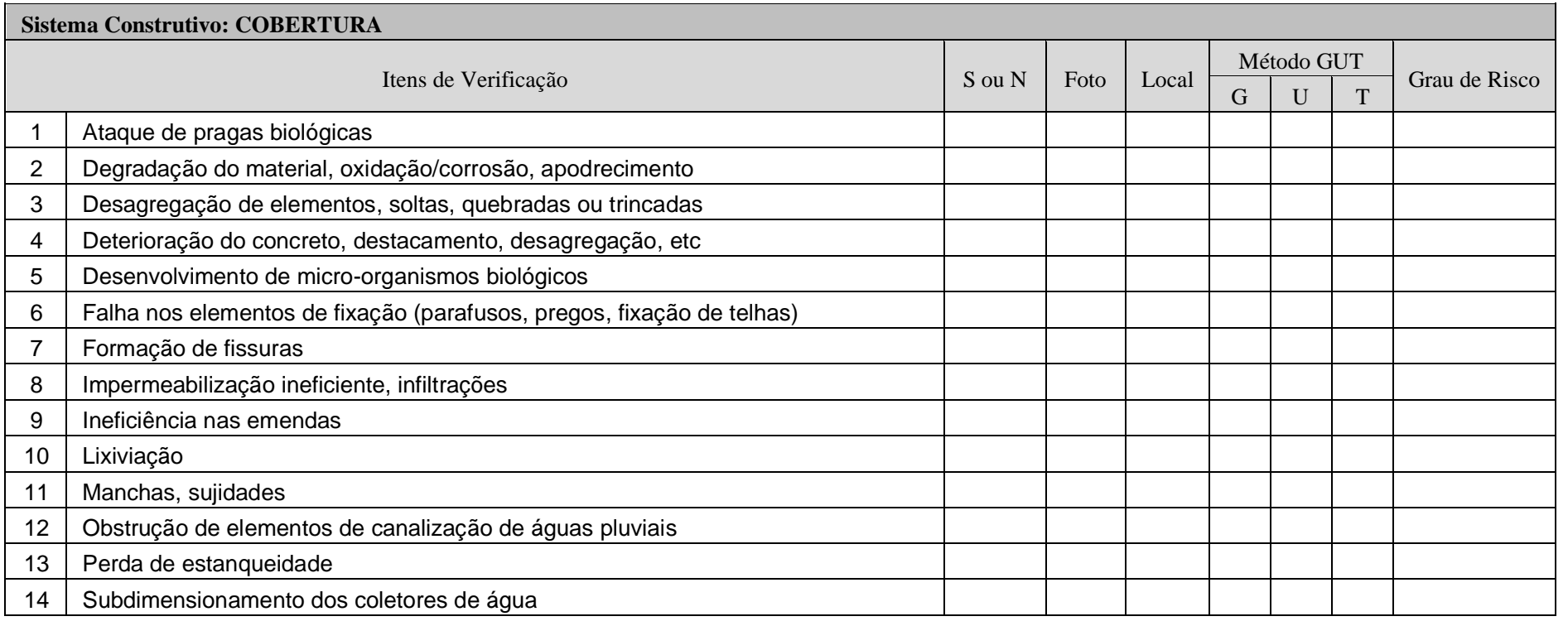


Quadro 5 - Checklist Reservatórios de Água

\begin{tabular}{|c|c|c|c|c|c|c|c|c|}
\hline \multicolumn{9}{|c|}{ Sistema Construtivo: RESERVATÓRIOS DE ÁGUA } \\
\hline \multirow{2}{*}{\multicolumn{2}{|c|}{ 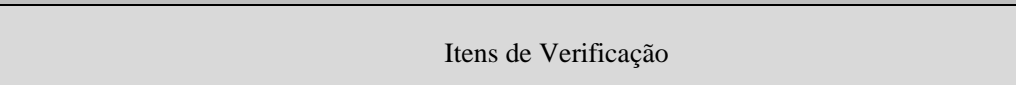 }} & \multirow{3}{*}{ S ou $\mathrm{N}$} & \multirow{3}{*}{ Foto } & \multirow{2}{*}{ Local } & \multicolumn{3}{|c|}{ Método GUT } & \multirow{2}{*}{ Grau de Risco } \\
\hline & & & & & G & $\mathrm{U}$ & $\mathrm{T}$ & \\
\hline 1 & Armadura exposta, corrosão das armaduras & & & & & & & \\
\hline 2 & Ausência da tampa dos reservatórios & & & & & & & \\
\hline 3 & Deterioração do concreto (destacamento, desagregação, etc ) & & & & & & & \\
\hline 4 & Eflorescência, manchas ou desenvolvimento de microrganismos biológicos & & & & & & & \\
\hline 5 & Formação de fissuras & & & & & & & \\
\hline 6 & Ineficiência tampa do reservatório | Estanque & & & & & & & \\
\hline 7 & Ineficiência tampa do reservatório | Porta de acesso & & & & & & & \\
\hline 8 & Ineficiência tampa do reservatório | Vedação (líquidos, insetos) & & & & & & & \\
\hline 9 & Irregularidades geométricas, falhas de concretagem & & & & & & & \\
\hline 10 & Laudo de estanqueidade dos reservatórios & & & & & & & \\
\hline 11 & Laudo de limpeza e desinfecção & & & & & & & \\
\hline 12 & Laudo de potabilidade da água & & & & & & & \\
\hline 13 & Tubulações de esgoto em reservatório de água potável & & & & & & & \\
\hline 14 & Tubulações de esgoto em reservatório de águas pluviais & & & & & & & \\
\hline 15 & Vazamento e infiltrações & & & & & & & \\
\hline 16 & Lixiviação & & & & & & & \\
\hline
\end{tabular}

Quadro 6 - Checklist Instalações Elétricas

\begin{tabular}{|c|c|c|c|c|c|c|c|c|}
\hline \multicolumn{9}{|c|}{ Sistema Construtivo: INSTALAÇÕES ELÉTRICAS } \\
\hline \multirow{2}{*}{\multicolumn{2}{|c|}{ Itens de Verificação }} & \multirow{3}{*}{$\mathrm{S}$ ou $\mathrm{N}$} & \multirow{2}{*}{ Foto } & \multirow{2}{*}{ Local } & \multicolumn{3}{|c|}{ Método GUT } & \multirow{2}{*}{ Grau de Risco } \\
\hline & & & & & $\mathrm{G}$ & $\mathrm{U}$ & $\mathrm{T}$ & \\
\hline 1 & Corrosão de tomadas e plugs & & & & & & & \\
\hline 3 & Desarme de disjuntores & & & & & & & \\
\hline 4 & Excesso de Benjamins (tês) em tomadas & & & & & & & \\
\hline 7 & Fios e cabos com partes sem isolamento/proteção & & & & & & & \\
\hline 8 & Fios e cabos expostos & & & & & & & \\
\hline 9 & Folgas em componentes de quadros & & & & & & & \\
\hline 10 & Quadro de medidores desatualizados & & & & & & & \\
\hline 11 & $\begin{array}{l}\text { Substituição de disjuntores por outros de maior capacidade, sem a troca dos } \\
\text { cabos pertinentes }\end{array}$ & & & & & & & \\
\hline 15 & Quadros com componentes desarrumados e sem identificação dos circuitos. & & & & & & & \\
\hline 16 & Quadros sem o disjuntor de proteção contra choque (DR) & & & & & & & \\
\hline 17 & Quadros sem tampa ou com fechaduras/dobradiças quebradas & & & & & & & \\
\hline 18 & Sobreaquecimento de cabos e fios e/ou dos componentes o quadro de distribuição & & & & & & & \\
\hline
\end{tabular}


Quadro 7 - Checklist Combate a Incêndio

\begin{tabular}{|c|c|c|c|c|c|c|c|c|}
\hline \multicolumn{9}{|c|}{ Sistema Construtivo: COMBATE A INCÊNDIO } \\
\hline \multirow{2}{*}{\multicolumn{2}{|c|}{ Itens de Verificação }} & \multirow{2}{*}{ S ou $\mathrm{N}$} & \multirow{2}{*}{ Foto } & \multirow{2}{*}{ Local } & \multicolumn{3}{|c|}{ Método GUT } & \multirow{2}{*}{ Grau de Risco } \\
\hline & & & & & G & $\mathrm{U}$ & $\mathrm{T}$ & \\
\hline 1 & Ausência de iluminação de emergência & & & & & & & \\
\hline 2 & Ausência de saída de emergência & & & & & & & \\
\hline 3 & Escadas sem ventilação exaustora & & & & & & & \\
\hline 4 & Extintores com acesso obstruído & & & & & & & \\
\hline 5 & Extintores descarregados/vencidos & & & & & & & \\
\hline 6 & Extintores instalados acima da altura $=1,60 \mathrm{~m}$ (ABNT 12.962) & & & & & & & \\
\hline 7 & Extintores sem indicação da classe & & & & & & & \\
\hline 8 & Extintores sem selo do INMETRO & & & & & & & \\
\hline 9 & Falta de sinalização indicativa de equipamentos & & & & & & & \\
\hline 10 & Fios e cabos amarrados às tubulações ou eletrodutos acima & & & & & & & \\
\hline 11 & Há o Certificado de Conformidade do Corpo de Bombeiros? & & & & & & & \\
\hline 12 & Hidrantes obstruídos & & & & & & & \\
\hline 13 & Iluminação de emergência sem funcionar & & & & & & & \\
\hline 14 & Obstrução da saída de emergência & & & & & & & \\
\hline 15 & Portas corta-fogo emperradas ou com problemas & & & & & & & \\
\hline 16 & $\begin{array}{l}\text { Portas corta-fogo que abrem para o interior do edifício, em vez para saída de } \\
\text { emergência }\end{array}$ & & & & & & & \\
\hline 17 & Portas corta-fogo sem selo do INMETRO & & & & & & & \\
\hline 18 & Portas de hidrantes não abrem a $180^{\circ}$ & & & & & & & \\
\hline 19 & Projeto do sistema & & & & & & & \\
\hline 20 & Quantidade insuficiente de extintores por pavimento ( 1 classe $A$ e 1 classe $B / C$ ) & & & & & & & \\
\hline 21 & Saída de Emergência com menos de $1,20 \mathrm{~m}$ de largura & & & & & & & \\
\hline 22 & Sprinklers com área de atuação obstruída & & & & & & & \\
\hline 23 & Sprinklers com detectores sujos ou pintados & & & & & & & \\
\hline
\end{tabular}

Quadro 8 - Checklist Esquadrias

\begin{tabular}{|c|c|c|c|c|c|c|c|c|}
\hline \multicolumn{9}{|c|}{ Sistema Construtivo: ESQUADRIAS } \\
\hline \multirow{2}{*}{\multicolumn{2}{|c|}{ Itens de Verificação }} & \multirow{2}{*}{$\mathrm{S}$ ou $\mathrm{N}$} & \multirow{2}{*}{ Foto } & \multirow{2}{*}{ Local } & \multicolumn{3}{|c|}{ Método GUT } & \multirow{2}{*}{ Grau de Risco } \\
\hline & & & & & G & $\mathrm{U}$ & $\mathrm{T}$ & \\
\hline 1 & Deterioração (desgaste do material, oxidação, corrosão) & & & & & & & \\
\hline 3 & Falha na fixação & & & & & & & \\
\hline 4 & Irregularidades geométricas (fora de prumo, nível, esquadro) & & & & & & & \\
\hline 7 & Presença de pragas em esquadrias de madeira & & & & & & & \\
\hline 8 & Falha nas vedações (borrachas, silicones, etc..) & & & & & & & \\
\hline
\end{tabular}


Quadro 9 - Checklist Estrutura de Concreto

\begin{tabular}{l} 
Sistema Construtivo: ESTRUTURAS DE CONCRETO \\
\multicolumn{2}{|c|}{ Itens de Verificação } & S ou N & Foto & Local & Método GUT & \multirow{2}{*}{ Grau de Risco } \\
\hline
\end{tabular}

Quadro 10 - Checklist Instalações de Gás

\begin{tabular}{|c|c|c|c|c|c|c|c|c|}
\hline \multicolumn{9}{|c|}{ Sistema Construtivo: INSTALAÇÕES DE GÁS } \\
\hline \multirow{2}{*}{\multicolumn{2}{|c|}{ Itens de Verificação }} & \multirow{2}{*}{ S ou $\mathrm{N}$} & \multirow{2}{*}{ Foto } & \multirow{2}{*}{ Local } & \multicolumn{3}{|c|}{ Método GUT } & \multirow{2}{*}{ Grau de Risco } \\
\hline & & & & & G & $\mathrm{U}$ & $\mathrm{T}$ & \\
\hline 1 & $\begin{array}{l}\text { Ausência do dispositivo de segurança (válvulas de bloqueio/ reguladores e } \\
\text { detectores) }\end{array}$ & & & & & & & \\
\hline 2 & Ausência de Teste de estanqueidade / Manutenção & & & & & & & \\
\hline 3 & Tubulações corroídas & & & & & & & \\
\hline 4 & $\begin{array}{l}\text { Tubulações de gás próximo de tubulações elétricas }(0,30 \mathrm{~m} \text { eletrodutos e } 0,50 \mathrm{~m} \\
\text { cabos nus) }\end{array}$ & & & & & & & \\
\hline 5 & Tubulações em contato com água & & & & & & & \\
\hline 6 & Tubulações enterradas sem proteção & & & & & & & \\
\hline 7 & Uso de cilindros de gás (botijões) dentro das unidades habitacionais & & & & & & & \\
\hline 8 & Obstrução dos medidores e registros & & & & & & & \\
\hline 9 & Vazamentos & & & & & & & \\
\hline
\end{tabular}

Quadro 11 - Checklist Instalações Hidráulicas

\begin{tabular}{l} 
Sistema Construtivo: INSTALAÇõES HIDRÁULICAS \\
\multicolumn{2}{|c|}{ Itens de Verificação } & \multirow{2}{*}{ S ou N } & \multirow{2}{*}{ Foto } & \multirow{2}{*}{ Local } & \multicolumn{2}{|c|}{ Método GUT } & \multirow{2}{*}{ Grau de Risco } \\
\hline
\end{tabular}


Quadro 12 - Checklist Manutenção

\begin{tabular}{|c|c|c|c|c|c|c|c|c|}
\hline \multicolumn{9}{|c|}{ Sistema Construtivo: MANUTENÇÃO } \\
\hline \multirow{2}{*}{\multicolumn{2}{|c|}{ Itens de Verificação }} & \multirow{2}{*}{$\mathrm{S}$ ou $\mathrm{N}$} & \multirow{2}{*}{ Foto } & \multirow{2}{*}{ Local } & \multicolumn{3}{|c|}{ Método GUT } & \multirow{2}{*}{ Grau de Risco } \\
\hline & & & & & G & $\mathrm{U}$ & $\mathrm{T}$ & \\
\hline 1 & Está coerente com normas técnicas? & & & & & & & \\
\hline 2 & Existe acesso aos equipamentos? & & & & & & & \\
\hline 3 & Há condições de segurança para realização da manutenção? & & & & & & & \\
\hline 4 & Há empresas especializadas em manutenção dos sistemas? & & & & & & & \\
\hline 5 & Há plano de manutenção? & & & & & & & \\
\hline 6 & Há registro gerado pelas atividades de manutenção? & & & & & & & \\
\hline 7 & Os ambientes estão limpos? & & & & & & & \\
\hline 8 & Os registros estão organizados e disponíveis? & & & & & & & \\
\hline 9 & Rotinas estão adequadas? & & & & & & & \\
\hline
\end{tabular}

Quadro 13 - Checklist Proteção Contra Descargas Atmosféricas

\begin{tabular}{|c|c|c|c|c|c|c|c|c|}
\hline \multicolumn{9}{|c|}{ Sistema Construtivo: PROTEÇÃO CONTRA DESCARGAS ATMOSFÉRICAS } \\
\hline \multirow{2}{*}{\multicolumn{2}{|c|}{ Itens de Verificação }} & \multirow{2}{*}{ S ou $\mathrm{N}$} & \multirow{2}{*}{ Foto } & \multirow{2}{*}{ Local } & \multicolumn{3}{|c|}{ Método GUT } & \multirow{2}{*}{ Grau de Risco } \\
\hline & & & & & G & $\mathrm{U}$ & $\mathrm{T}$ & \\
\hline 1 & A edificação possui SPDA? & & & & & & & \\
\hline 2 & A edificação requer o uso de SPDA? & & & & & & & \\
\hline \multirow[t]{2}{*}{3} & Corrosão nos cabos de cobre nus de descida & & & & & & & \\
\hline & Cabos e base de sustentação do captador com presença de corrosão & & & & & & & \\
\hline 4 & $\begin{array}{l}\text { Deficiência de equipotencialidade - Verificar a existência do terminal de } \\
\text { aterramento. }\end{array}$ & & & & & & & \\
\hline 5 & $\begin{array}{l}\text { Disparidades na medição da resistência ôhmica junto às hastes nas caixas de } \\
\text { inspeção - Verificar caixa de aterramento }\end{array}$ & & & & & & & \\
\hline 6 & Ausência de empresa de manutenção & & & & & & & \\
\hline 7 & $\begin{array}{l}\text { Falta de proteção das descidas externas junto às fachadas, próximo ao passeio - } \\
\text { evitar impactos e rompimento }\end{array}$ & & & & & & & \\
\hline 8 & Fixação de hastes diretamente na laje de cobertura & & & & & & & \\
\hline 9 & Ausência de manutenção preventiva & & & & & & & \\
\hline
\end{tabular}

\section{CONCLUSÃO}

Com o presente artigo, busca-se contribuir para a melhoria das inspeções prediais, gerando um conjunto de checklists, que sirvam de ferramenta orientativa e para gestão das informações, durante as inspeções in loco, conduzindo o processo de inspeção.

É importante ressaltar, que os modelos desenvolvidos possuem como base, edificações residenciais verticais com a tipologia construtiva do Brasil, requerendo ser adaptada para as demais localidades. No entanto, a ferramenta possui ampla aplicabilidade em qualquer tipologia de obra e sistemas construtivos, caracterizando-se como um estudo agregativo exploratório e amplo.

Apesar do estudo propor modelos de checklist para sistemas construtivos, é importante ressaltar que antes de realizar uma inspeção predial, o inspetor responsável deverá analisar as condições de conservação e manutenção da edificação, os sistemas e tecnologias presentes, como também, as ferramentas e nível de inspeção demandados.

Por fim, destaca-se a ausência de bibliográficas acerca do tema, havendo uma lacuna da produção científica nacional e internacional, voltada para a inspeção predial. 


\section{REFERÊNCIAS}

ASSOCIAÇÃO BRASILEIRA DE NORMAS TÉCNICAS - NBR 13575:2015: Desempenho das Edificações. Rio de Janeiro, 2015.

ASSOCIAÇÃO BRASILEIRA DE NORMAS TÉCNICAS - NBR 5674:2012: Manutenção de Edificações - Procedimento. Rio de Janeiro, 2012.

BALLADO, K.; TRUPP, T.; LIU, L. Mobile and sensor-based infraestructure inspections. Construction Research Congress ASCE, 2003. 8p.

BÖES, J. S. Building Inspection: an integrative methodology for identification and prioritization of pathological manfestations in buildings. XIII International Conference on Structural Repair and Rehabilitation (CINPAR), Crato, 2017.

BÖES, J. S. Inspeção Predial: da teoria à prática. Curso de extensão. Faculdade Ari de Sá (FAS), Fortaleza, 120p. 2017.

GOMIDE, T. L. F.; NETO, J. C. P. F.; GULLO, M. A. Inspeção Predial Total. PINI, São Paulo, 2014.

INSTITUTO BRASILEIRO DE AVALIAÇÕES E PERÍCIAS DE ENGENHARIA (IBAPE). Norma de Inspeção Predial Nacional. São Paulo, 2012.

INSTITUTO BRASILEIRO DE AUDITORIA DE ENGENHARIA (IBRAENG). Inspeção Predial e Auditoria Técnica Predial. Fortaleza, 2015.

KEPNER, C.; TREGOE, B. O novo administrador racional. São Paulo: Makron Books, 1991.

PACHECO; L. S.; OLIVEIRA, C. S. P.; SILVA FILHO, L. C. Estudo comparativo de leis de inspeção predial no Brasil e na Espanha. Congresso Brasileiro do Concreto - CBC2013, Gramado, Brasil: outubro 2013.

SUNKPHO, J.; GARRETT JR, J. H.; McNeil, S. XML-Based Inspection MOdeling for Developing Field Inspection Support Systems. Journal of Infrastructure Systems, Vol. 11, n. 3; p. 190-200, Sep. 2005.

STEINBERG, D. Creating a bridge inspection program. Structures Congress 2009: Don't mess with structural engineers, p. 480-484, 2009.

VERZOLA, S. N.; MARCHIORI, F. F.; ARAGON, J. O. Proposta de lista de verificação para inspeção predial $\mathbf{x}$ urgência das manutenções. XV Encontro Nacional de Tecnologia do Ambiente Construído ENTAC. Maceió, 2014. 